\title{
A means-end chain approach to explaining the adoption of good agricultural practices certification schemes: the case of Malaysian vegetable farmers
}

\begin{abstract}
Good agricultural practices (GAP) certification schemes have been promoted to enhance agricultural sustainability. This study seeks to explain the adoption of GAP certification schemes through an analysis of the role of personal values in guiding such choice. It is a departure from approaches taken in previous studies in the area. Through the laddering interview technique of means-end chain analysis, a hierarchical value map was systematically schematized to illustrate the relationship between adoption of GAP (attributes), outcomes (consequences), and personal values driving the choice. The personal values identified in this study cluster under the headings of ñbetter lifeò, ñreligious responsibilityò, ñhealthy lifeò, and ñesponsible farmerò. Amongst these, the main evidence (pathways) pointed to the desire to have ñbetter lifeò through the enhanced financial position that is perceived to arise as a consequence of GAP adoption as being of primary importance. These findings suggest that, while profit is not the sole end driver of adoptive behavior, GAP certification schemes have to be seen as lucrative and to enhance the goals of achieving core personal values. Other empirical information in this study also has significant policy implications. It is a key finding of this paper that effective promotions of GAP should be tailored and targeted at specific segments of the farmer population.
\end{abstract}

Keyword: Certification scheme; Good agricultural practices; Means-end chain; Personal values; Vegetable farmers 